\section{Transtorno Bipolar - Teoria e Clínica}

Flávio Kapczinski e João Quevedo (Organizadores). Artmed Editora; 2009.

Flávio Kapczinski e João Quevedo desenvolveram um excelente trabalho como organizadores da obra "Transtorno Bipolar - Teoria e Clínica" - esta foi minha mais forte impressão ao analisá-la. Afinal, é muito difícil manter a homogeneidade da apresentação dos capítulos, quando estes são de autoria de diversos especialistas, brasileiros e estrangeiros. Os autores tendem, de forma natural, a impor um ritmo próprio ao seu texto; ainda mais em se tratando de especialistas na área, como Eduard Vieta (Barcelona) e Jair Constante Soares (Carolina do Norte), só para ficar nos colaboradores internacionais mais conhecidos. Isto pode resultar em capítulos, embora profundos e precisos em conteúdo, de estrutura extremamente diversa, comprometendo a formatação final de obra em um "livro" (muitos acabam se parecendo mais uma coletânea de textos). "Transtorno Bipolar - Teoria e Clínica" não padece deste defeito, ao contrário, lembra muito mais um "livro de autor" e não uma obra realizada em colaboração.

Os organizadores foram felizes na escolha dos seus colaboradores, pois embora oriundos de diversos centros de excelência em transtorno bipolar espalhados pelo Brasil e exterior, tenderam (em certo número) a pertencer a determinados grupos de pesquisa (como o Hospital de Clínicas de Porto Alegre, o Hospital das Clínicas da Faculdade de Medicina da Universidade de São Paulo e o Hospital de Clínicas de Barcelona); os especialistas de outras instituições, é claro, também foram excelentes colaboradores, mas autores de uma mesma instituição tendem a redigir de forma mais parecida, de certa forma facilitando a coerência global da obra.

Os capítulos, além da qualidade técnica, têm destaques, tabelas, gráficos e esquemas sinóticos muito úteis, além de vinhetas clínicas, quando cabível. A bibliografia é atualizada e as principais referências (para aprofundamento no tema) estão em destaque. Sendo assim, o livro pode se destinar tanto ao especialista em transtornos do humor que deseja uma consulta rápida a algum tema específico - permitindo uma eficiente consulta às referências sobre o assunto (se assim o desejar) -, quanto ao psiquiatra clínico e ao residente em psiquiatria, pois os capítulos permitem uma visão concisa e precisa, em uma leitura rápida e agradável. Vale destacar, portanto, que os capítulos individuais podem (e devem) ser lidos também como resumos sobre um assunto relevante na doença bipolar, embora formem um bom conjunto, como destacado acima.

Para os psiquiatras acostumados a livros com um viés quase que totalmente clínico, chama a atenção o capítulo 2, "Modelos Animais do Transtorno Bipolar". À primeira vista parece um pouco exagerado em profundidade e deslocado do conjunto, mas se revela uma das leituras mais interessantes. Contudo, o psiquiatra clínico, com necessidades de informação muito mais diretas e objetivas, pode prescindir da leitura deste capítulo sem prejuízo à compreensão dos demais; a "teoria" do subtítulo da obra está contemplada sem atrapalhar o aprendizado "clínico".

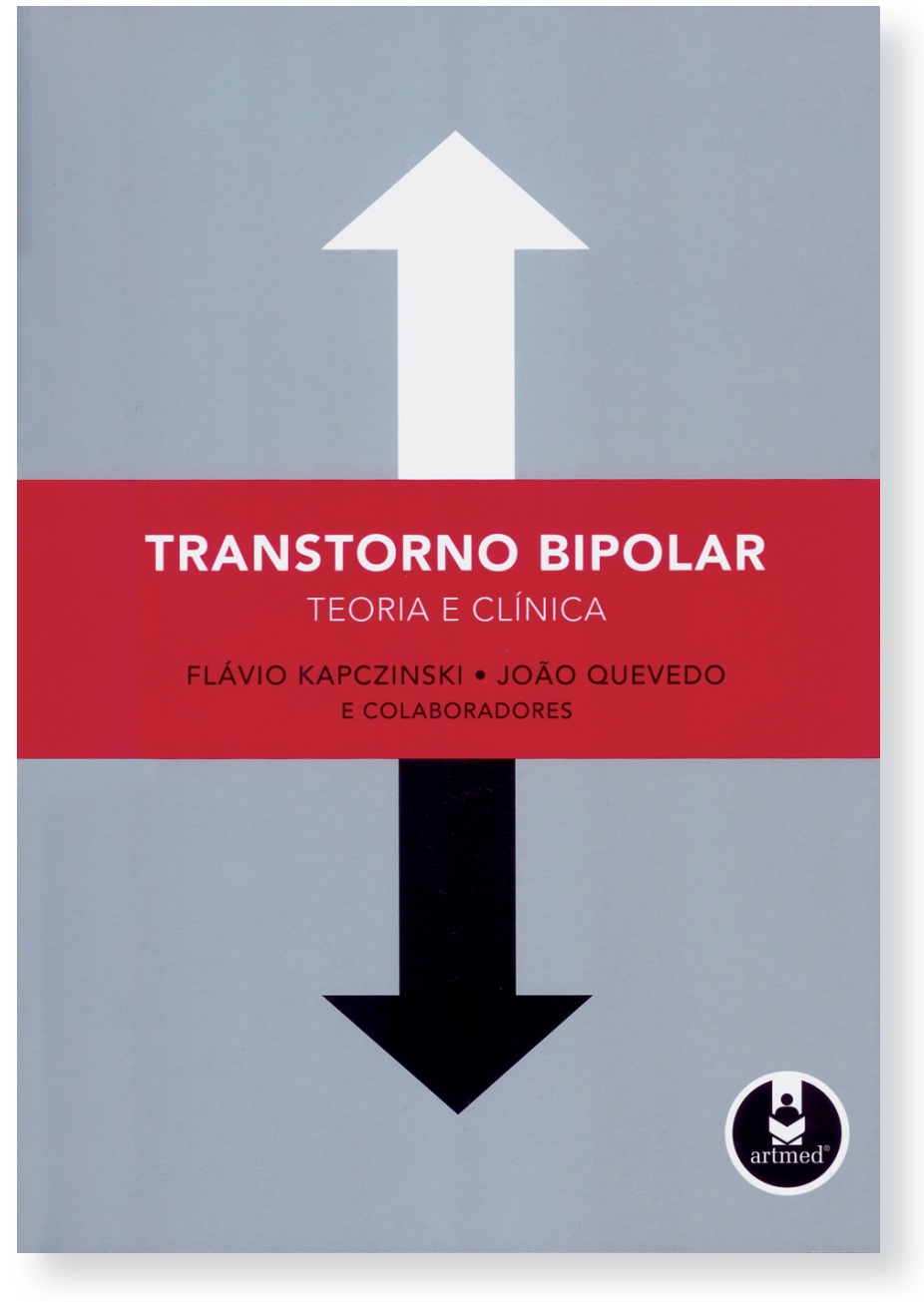

"Transtorno Bipolar - Teoria e Clínica" é de grande utilidade para o especialista em transtornos do humor, para o psiquiatra em geral que deseja se aprofundar no tema e para a consulta do psiquiatra clínico e do residente, que poderão obter uma "referência rápida" e subsídios para futuros estudos, se o desejar. Com certeza é uma excelente aquisição para uma biblioteca particular ou institucional.

Frederico Navas Demetrio Instituto de Psiquiatria, Hospital das Clínicas, Faculdade de Medicina, Universidade de São Paulo (FMUSP), São Paulo (SP), Brasil

Grupo de Doenças Afetivas (GRUDA), Instituto de Psiquiatria, Hospital das Clínicas, Faculdade de Medicina, Universidade de São Paulo (FMUSP), São Paulo (SP), Brasi 